\title{
Design of a Compact CPW-Fed Monopole Antenna With Asymmetrical Hexagonal Slot Loaded Ground Structure for $\mathrm{C} / \mathrm{X} / \mathrm{Ku}$ Band Applications
}

\author{
Ajay Kumar Dwivedi (Doctoral Student, Department of Electronics and Communication, Indian Institute \\ of Information Technology Allahabad, Prayagraj, Uttar Pradesh, India), \\ Brijesh Mishra (Assistant Professor, Department of Electronics and Communication, Madan Mohan \\ Malaviya University of Technology, Gorakhpur, Uttar Pradesh, India), \\ Vivek Singh* (Assistant Professor, Department of Electronics and Communication, Shambhunath Institute \\ of Engineering and Technology, Prayagraj, Uttar Pradesh, India), \\ Pramod Narayan Tripathi (Doctoral Student, Department of Radio Engineering and Cybernetics, Moscow \\ Institute of Physics and Technology, Moscow, Russia), \\ Ashutosh Kumar Singh (Assistant Professor, Department of Electronics and Communication, Indian \\ Institute of Information Technology Allahabad, Prayagraj, Uttar Pradesh, India)
}

\begin{abstract}
A novel design of ultra-wideband CPW-fed compact monopole patch antenna is presented in the article. The size of the antenna is $22 \times 18 \times 1.6 \mathrm{~mm}$ and it operates well over an ultra-wideband frequency range $4.86-13.66 \mathrm{GHz}$ (simulated) and 4.93-13.54 GHz (measured) covering $C, X$ and partial $\mathrm{Ku}$ band applications. The proposed design consists of a defected ground plane and $U$-shape radiating patch along with two square shape parasitic patches in order to achieve the ultra-wideband (UWB) operations. The performance matrix is validated through measured results that indicate the wide impedance bandwidth (93.2\%) with maximum gain of $4 \mathrm{dBi}$ with nearly $95 \%$ of maximum radiation efficiency; moreover, the 3D gain pattern manifests approximately omni-directional pattern of the proposed design. The prototype has been modelled using HFSS (High Frequency Structure Simulator-18) by ANSYS, fabricated and tested using vector network analyser E5071C.
\end{abstract}

Keywords - Anechoic chambers; Antenna measurements; Antenna radiation patterns; Gain; Group delay; Ultra-Wideband antennas.

\section{INTRODUCTION}

Advancement in printing technology has led to the resurgence in the research field of planar antenna. Printing technology is developing at a rapid pace with improved antenna performance for different areas of applications. Micro strip antenna is widely preferred for RF energy harvesting [1], [2], system, medical applications [3], wireless communication [4], radio-frequency identification (RFID) [5] and smart devices [6]. Researchers are working to reduce the overall antenna size and to accommodate the multiple applications into a single unit to avoid the use of multiple devices. Ultra- wideband (UWB) antenna offers specific advantages in terms of signal robustness, high data rate, signal distortion and ease of fabrication [7]. Many efforts are underway to search for new antenna structures in order to meet the challenging needs of smart devices, which are compatible with modern wireless communications. In particular, wideband, multiband and ultrawideband antennas are generally preferred in MMICs and small devices [8].

In general, UWB antenna is useful to transmit a very narrow pulse in nanosecond at a high data rate and low energy consumption [8]. The UWB technology is defined by the Federal Communications Commission (FCC) report for transmitting information over electromagnetic spectrum with large bandwidth $(>500 \mathrm{MHz})$ or pp $20 \%$ of the arithmetic centre frequency [9]. In the development of antenna technology, some authors have reported a new design of UWB antenna for different applications; some of them are a dual band shared aperture antenna for RFID reader [10], a CPWfed flexible UWB antenna for Internet of Things (IOT) applications [11], a compact design of UWB antenna for WLAN/WiMAX and satellite applications [12], a multi-slot loaded micro strip antenna for ultra-wideband applications [13], a compact umbrella shaped UWB antenna for groundcoupling GPR applications [14].

In the present research, a compact $(22 \times 18) \mathrm{mm} \mathrm{CPW}$-fed monopole antenna for $\mathrm{C} / \mathrm{X} / \mathrm{Ku}$ band applications is propounded. Asymmetrical hexagonal slot loaded defected ground structure has been used in the present research wherein slots and notches of different sizes have been loaded on radiating patch to make this design unique. The proposed

\footnotetext{
${ }^{*}$ Corresponding author.

E-mail: vivek.10singh@gmail.com
} 
UWB antenna structure comprises CPW-fed U-shape radiating patch with two parasitically coupled square patches and asymmetrical hexagonal shape slot loaded defected ground structure. Performance of the proposed antenna is analysed in terms of surface current distribution, return loss, radiation pattern, gain and radiation efficiency. Antenna geometry, analysis and results are discussed in foregoing sections.

\section{ANTENNA DESIGN AND CONFIGURATION}

The proposed CPW-fed antenna geometries for ultrawideband operation are shown in Fig. 1(a) and (b). In the present research, an asymmetrical hexagonal structure is etched out from the ground plane (bottom plane) and U-shape geometry has been incorporated on the radiating patch (top plane) to operate antenna in $\mathrm{C} / \mathrm{X} / \mathrm{Ku}$ bands. Two parasitic elements each of $(4 \times 4) \mathrm{mm}$ have been used to make this antenna suitable for ultra-wideband applications. Antenna is fabricated on FR-4 epoxy substrate $(22 \times 18) \mathrm{mm}$ and simulated results have been validated with experimental results. Front and back view of fabricated photographs of the proposed antenna are presented in Fig. 1(c) and (d), respectively.

The complete design of the proposed antenna is finalised after the analysis of microwave theory and the execution of several steps (cf., Fig. 2(a)) to meet our expectations. Simulated return loss versus frequency analysis is presented in Fig. 2(b) for antenna designs 1-4. The analysis has been performed to optimise the antenna configuration; Antenna 4 has been chosen as the proposed antenna.
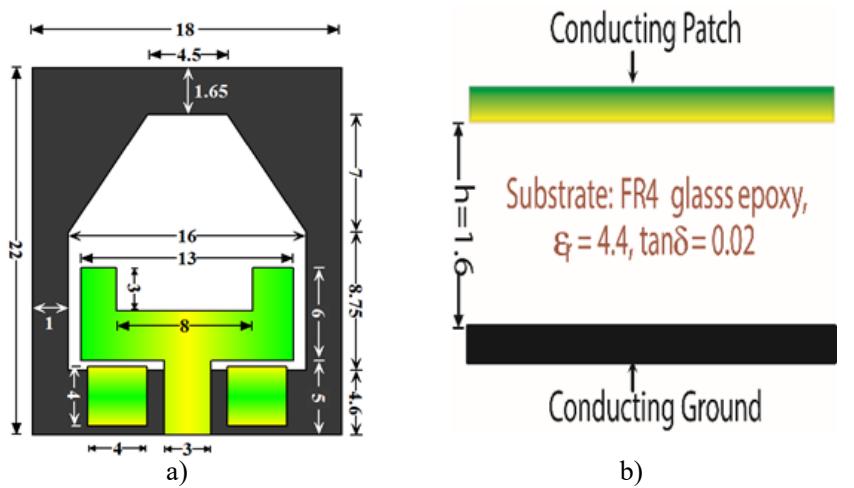

b)

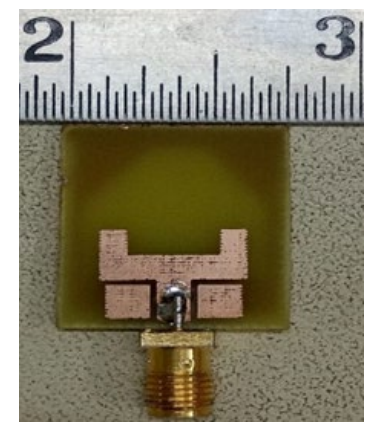

c)

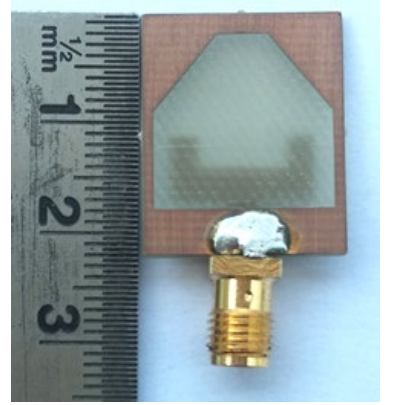

d)

Fig. 1. Geometry of the proposed antenna (dimensions are in $\mathrm{mm}$ ): a) Front view geometry of the proposed antenna; b) Side view geometry of the proposed antenna; c) Front view photograph of the proposed antenna; d) Back view photograph of proposed antenna.
Through the perusal of Fig. 2(b), it is clearly observed that the return loss of Antenna 1 is not enough $(>-10 \mathrm{~dB})$ for any practical use, whereas a dual band behaviour is observed for Antennas 2 \& 3.

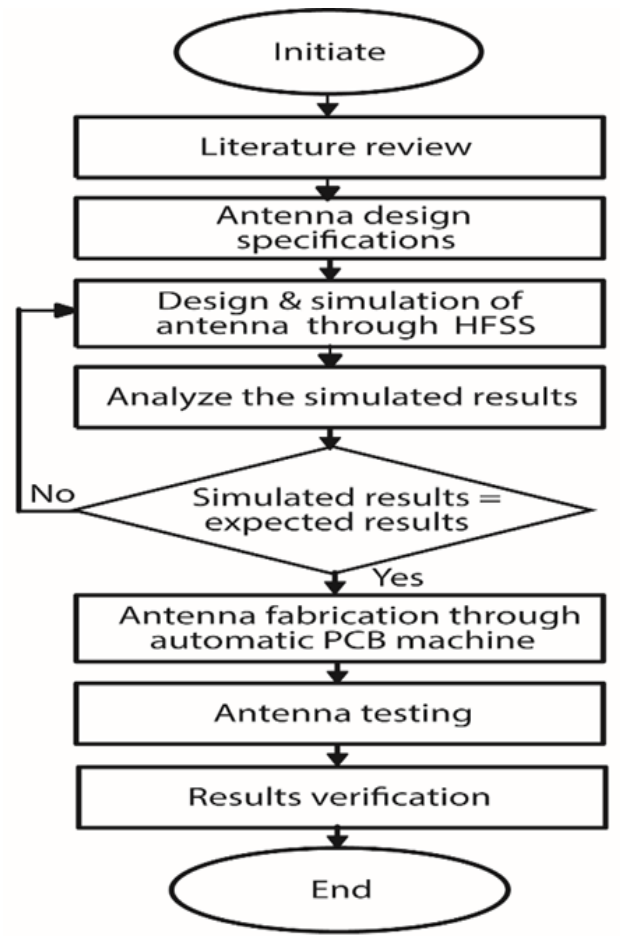

a)

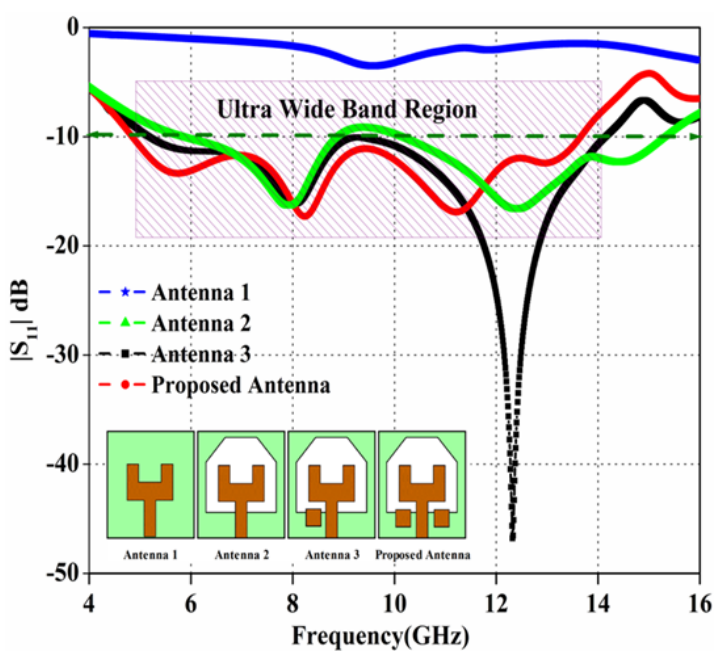

b)

Fig. 2. a) Flow chart of antenna design; b) Stepwise structure growth to analyse the proposed antenna.

Antenna 1 has been designed without defected ground plane and parasitic elements, whereas Antenna 2 has been designed with the defected ground plane in the absence of parasitic elements. In Antenna 3, only one parasitic element on the left side of the feed produces a dual band with a return loss of $-47 \mathrm{~dB}$, but it still fails to produce ultra-wideband. To obtain the best return loss and radiation along radiating patch, identical parasitic elements are gap coupled with both the edges of feed. In Antenna 4, symmetrical parasitic elements 
introduce the same phase delay and the overall pattern of the proposed antenna superimposes the individual patterns and tends to remain symmetrical. We observe an ultra-wideband behaviour (4.86-13.66 GHz) in Antenna 4 and the best return loss $(<-10 \mathrm{~dB})$ over operating frequencies.

\section{EFFECTS OF DEFECTED GROUND STRUCTURE (DGS) ON ANTENNA PERFORMANCE}

Slots, shapes and defects on the ground plane of antenna are referred to as defected ground structure (DGS). DGS is one of the emerging techniques to improve the antenna parameters like narrow bandwidth. The defect on the ground plane leads to the change in current path of ground plane; this may alter the lumped element value $(R, L$ and $C$ ) of equivalent circuit model of micro strip patch antenna. The defected ground structure gives rise to inductance value $(L)$ but reduces the capacitance value $(C)$ at the same time. Reduction in the capacitance value increases the bandwidth $\left(f-f_{\mathrm{c}}\right)\left(f+f_{\mathrm{c}}\right)$ of micro strip patch antenna as represented in Equation (3). Significant change in impedance bandwidth is observed with large change in $L$ and $C$ of DGS lumped equivalent circuit model and current distributions along a radiation patch. Therefore, DGS technique is the most useful technique for bandwidth enhancement of micro strip patch antenna and for microwave devices.

Equivalent circuit RLC model and elemental values of defected ground structure are reported as in [15].

$$
\begin{gathered}
R=\frac{2 Z_{\mathrm{c}}}{\sqrt{\frac{1}{\left|S_{11}{ }^{2}\right|}}-\left[2 Z_{\mathrm{c}}\left(2 \pi f C-\frac{1}{2 \pi f L}\right)\right]^{2}-1} \\
L=\frac{1}{(2 \pi f)^{2} C} \\
C=\frac{f_{\mathrm{c}}}{4 Z \pi\left(f^{2}-f_{\mathrm{c}}{ }^{2}\right)},
\end{gathered}
$$

where

$$
\begin{aligned}
& f \text {-resonance frequency; } \\
& f_{\mathrm{c}} \text { - cut-off frequency; } \\
& R \text { - resistance; } \\
& L \text { - inductance; } \\
& C \text { - capacitance. }
\end{aligned}
$$

In the paper, Antenna 1 and Antenna 2 are realised with and without defected ground structure and the simulated results of return loss are presented in Fig. 2(b). Antenna 2 provides a better return loss level $(-17 \mathrm{~dB})$ as compared to the return loss in Antenna 1 with level of $(-3.9 \mathrm{~dB})$.

A very large bandwidth $(9.4 \mathrm{GHz}$ with $1.42 \mathrm{GHz}$ notch band) is observed for Antenna 2, whereas $-10 \mathrm{~dB}$ bandwidth is absent for the case of Antenna 1, which suggests that Antenna 1 is not useful for any practical application. The defected ground structure directly affects the antenna performance like return loss $\left|\mathrm{S}_{11}\right|$ and bandwidth, which is in consonance with DGS facts ( $c f$. Eqs. (1)-(3)).
The suppressed E-plane \& H-plane cross-polarization level of the proposed antenna at resonating frequency of $5.7 \mathrm{GHz}$, 8.2 GHz and $11.2 \mathrm{GHz}$ is observed in Fig. 7 (a-f). The role of DGS is not limited but also finds some other applications in the field of micro strip antennas like multiband behaviour, bandwidth enhancement, gain enhancement, mutual coupling suppression, harmonics suppression in higher mode, crosspolarization level suppression and notched band creation.

\section{RESUlTS AND DISCUSSION}

The performance of the proposed antenna is analysed in terms of surface current distribution, return loss, input impedance, antenna gain, radiation efficiency and radiation pattern. Antenna testing is performed in microwave lab (vector network analyser E5071C and anechoic chamber) and simulated results have been validated with experimental results.

Distributed surface current density for the proposed antenna at $5.7 \mathrm{GHz}, 8.2 \mathrm{GHz}$ and $11.2 \mathrm{GHz}$ resonating frequencies, respectively, is shown in Fig. 3(a), (b) and (c). It has been observed that at $5.7 \mathrm{GHz}$ and $8.2 \mathrm{GHz}$ resonance frequency only U-shaped radiating patch is radiating maximum energy and $88.5 \mathrm{~A} / \mathrm{m}$ ( $c f$. , Fig. 3(a)) \& 94.7 A/m (cf., Fig. 3(b)) peak current density, respectively, is observed. At $11.2 \mathrm{GHz}$ resonance frequency, the parasitic elements are energised by the driven patch and maximum current density $(76.6 \mathrm{~A} / \mathrm{m})$ is flowing along the vertical axis. A better return loss response $(-16.5 \mathrm{~dB})$ and high surface current strength $(94.7 \mathrm{~A} / \mathrm{m})$ at 8.2 GHz is observed in Fig. 4(b) and Fig. 3(b), respectively.

Return loss response in Fig. 4(b) is in conformity with results observed in Fig. 3(b).

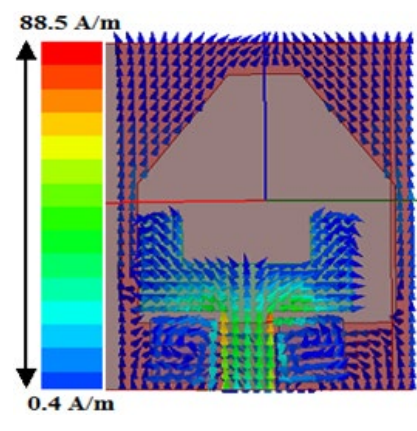

a)

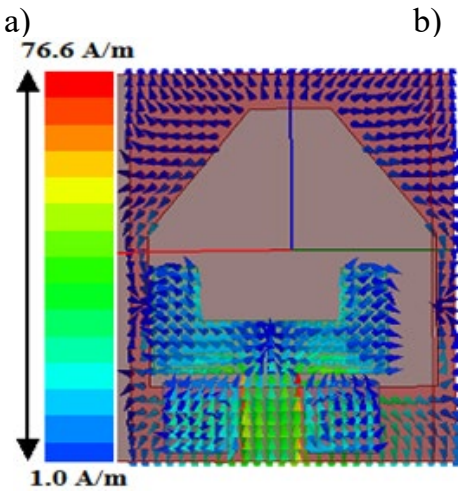

c)

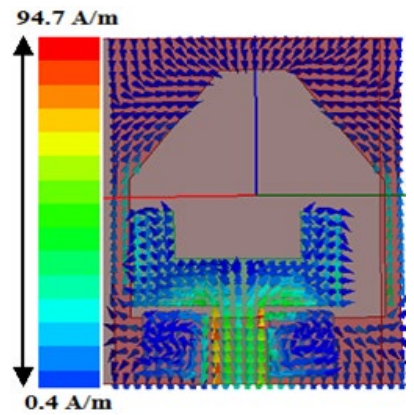

b)
Fig. 3. Surface current density distributions of the proposed antenna at resonating frequencies a) $5.7 \mathrm{GHz}$; b) $8.2 \mathrm{GHz}$; ) $11.2 \mathrm{GHz}$. 
The experimental return loss result photograph and the simulated and measured return loss graph are presented in Fig. 4(a) \& (b), respectively. From the perusal of Fig. 4(a) \& (b) the simulated frequency band $4.86-13.60 \mathrm{GHz}$ with $94.6 \%$ impedance bandwidth and measured frequency band 4.93 $13.54 \mathrm{GHz}$ with $93.2 \%$ impedance bandwidth are observed. The presented results make the antenna suitable for three different bands, namely, $\mathrm{C}, \mathrm{X}$ and $\mathrm{Ku}$ bands.

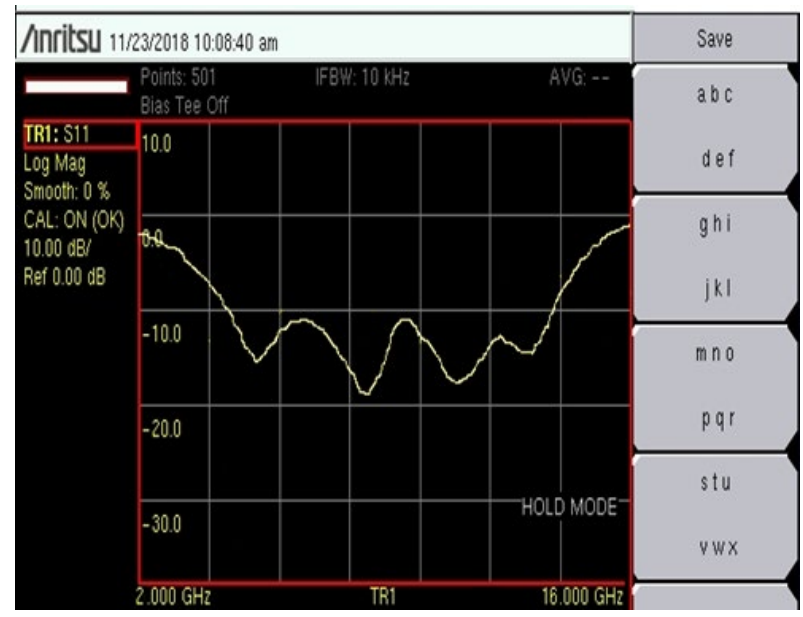

a)

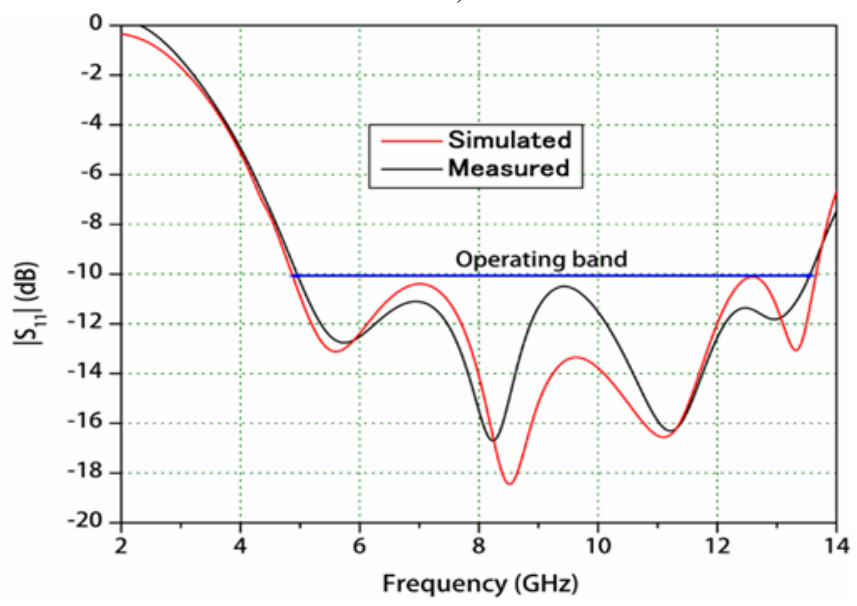

b)

Fig. 4. a) Photograph of experimental result of return loss; b) Simulated and measured return loss of the proposed antenna.

Radiation efficiency is a measure of the power radiated through the antenna as an electromagnetic wave, when the power is fed to the antenna terminals. If an antenna could be made as a totally ideal electrical component, it would transform all of the power fed to its terminals to a radiating electromagnetic energy that propagates into the surrounding space. This is a theoretical concept, whereas in real life some of the power fed to the antenna terminals is always lost due to the mismatch between the antenna element and the feeding network, which results in power losses, cable loss, material losses and so on. All together these losses lead to an error between the simulated and the measured results of antenna parameters.
The antenna efficiency is measured in an anechoic chamber by feeding some power to the antenna feed pads and measuring the strength of the radiated electromagnetic field in the surrounding space.

Figure 5(a) \& (b) depicts the simulated and measured gain and radiation efficiency of the proposed antenna. Inset of Fig. 5(a) presents a photograph of antenna measurement in an anechoic chamber. Simulated and measured antenna gains are presented in Fig. 5(a) and a maximum of $4 \mathrm{dBi}$ gain is observed at $12 \mathrm{GHz}$. Figure 5(b) illustrates the simulated and measured radiation efficiencies that are varying from $77 \%$ to $93 \%$ and from $77 \%$ to $95 \%$, respectively, in the entire frequency range 4.8 to $13.6 \mathrm{GHz}$.

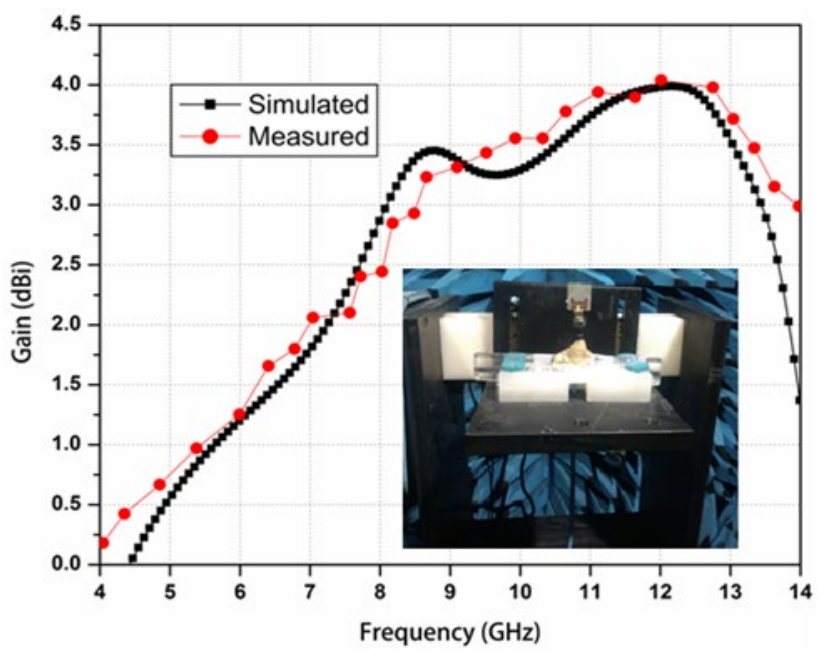

a)

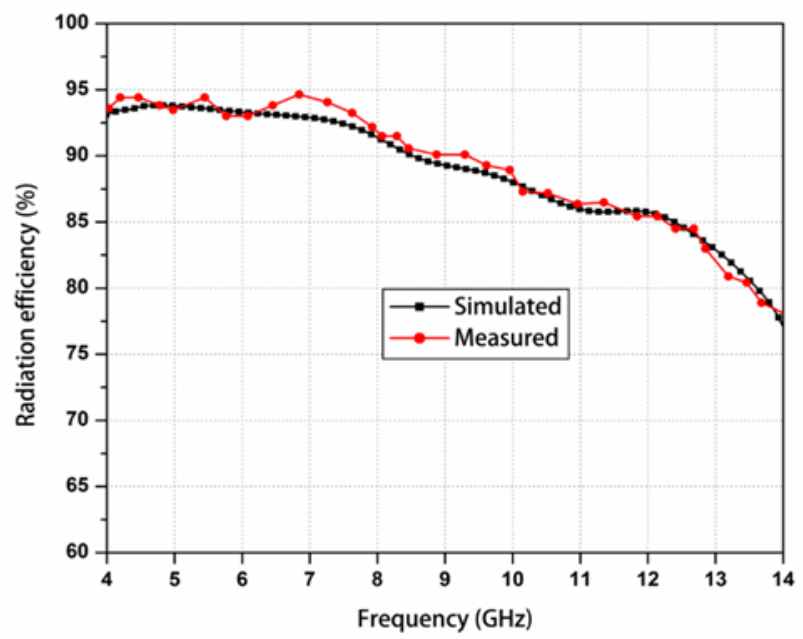

b)

Fig. 5. a) Antenna gain versus frequency plot of the proposed antenna; b) Simulated and measured radiation efficiency plot of the proposed antenna. 


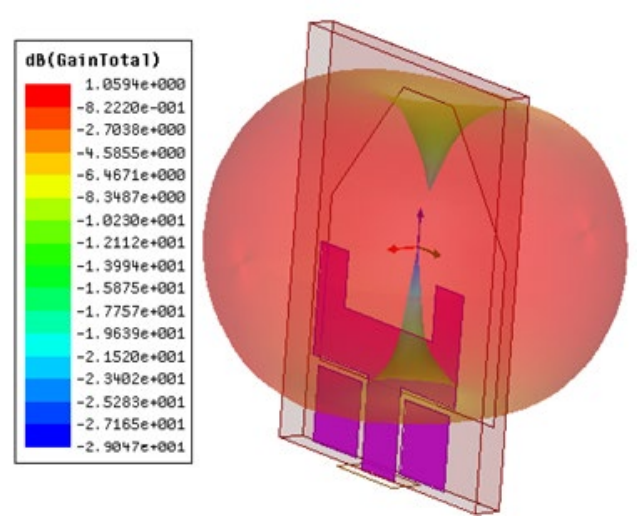

a)

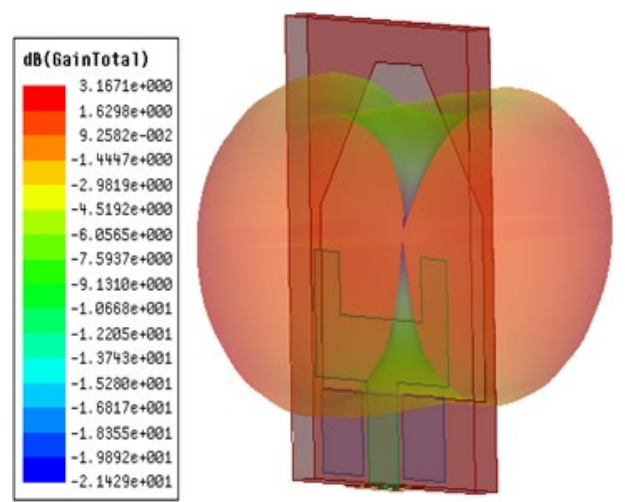

b)

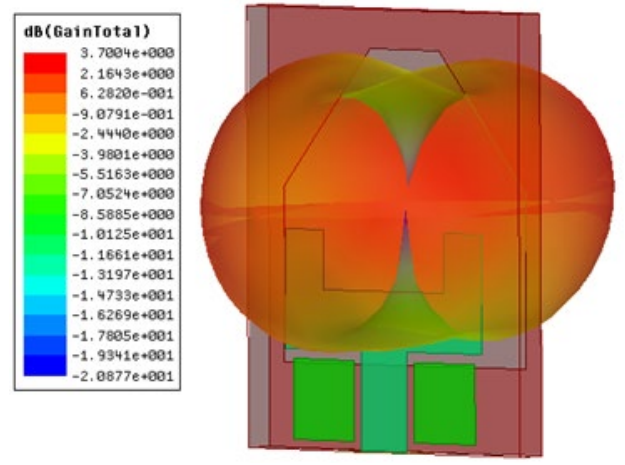

c)

Fig. 6. Simulated 3D gain of the proposed antenna at a) $5.7 \mathrm{GHz}$, b) $8.2 \mathrm{GHz}$, c) $11.2 \mathrm{GHz}$.

Figure 6(a), (b) \& (c) represents the simulated 3D gain variation with respect to different theta and phi value at three resonating frequencies of $5.7 \mathrm{GHz}, 8.2 \mathrm{GHz}$ and $11.2 \mathrm{GHz}$, respectively.

Due to losses in measuring instruments, fabrication process, dielectric materials, connecting probes and directional mismatch, a marginal variation between simulated and measured results is observed in Figs. 4(b), 5(a) \& 5(b). A maximum percentage difference of $22.7 \%$ (measured and simulated return loss of $-10.51 \mathrm{~dB}$ and $-13.6 \mathrm{~dB}$ is observed respectively, at $9.3 \mathrm{GHz}$ frequency) is between experimental and simulated return loss; $3.5 \%$ difference $(300 \mathrm{MHz}$ frequency shift) is between measured and simulated resonant frequency. In Fig. 6(a), $45 \%$ difference is observed between measured $(2.93 \mathrm{dBi}$ gain at $8.4 \mathrm{GHz})$ and simulated $(3.38 \mathrm{dBi}$ gain at $8.4 \mathrm{GHz}$ ) gain and in Fig. 5(b), $1.84 \%$ difference is observed between measured $(94.84 \%$ at $6.8 \mathrm{GHz})$ and simulated $(93 \%$ at $6.8 \mathrm{GHz})$ radiation efficiency. Percentage difference between simulated and experimental results is well within the permissible limits of error.

The simulated and measured radiation patterns (copolarization and cross-polarization) in the (E-plane) and (Hplane) of the proposed antenna for three resonating frequencies are observed in Fig. $7(\mathrm{a}-\mathrm{f})$. A sufficient difference is observed between co-polarization level and cross-polarization level (in $\mathrm{dB}$ ) in both E-plane and H-plane. The radiation patterns in E-plane \& H-plane for $5.7 \mathrm{GHz}$, $8.2 \mathrm{GHz}$ and $11.2 \mathrm{GHz}$ show omni-directional and good broadside radiation pattern behaviour with desirable low cross-polarization levels.

Maximum surface current distribution of $94.7 \mathrm{~A} / \mathrm{m}$ is observed in the proposed antenna at $8.2 \mathrm{GHz}$ (cf. Fig. 3(b)) and it is confirmed by the observation of simulated and measured radiation pattern curve for antenna at the same resonating frequency $(c f$. Fig. $7(\mathrm{c}, \mathrm{d}))$. The result observed in Fig. 7(c, d) is in conformity with the current distributions on the radiating patch in Fig. 3(b). Mapping between Fig. 7(c) \& 7(d) and Fig. 3(b) of the proposed antenna demonstrates that if surface current strength is high then antenna will radiate more power at the same resonating frequency.

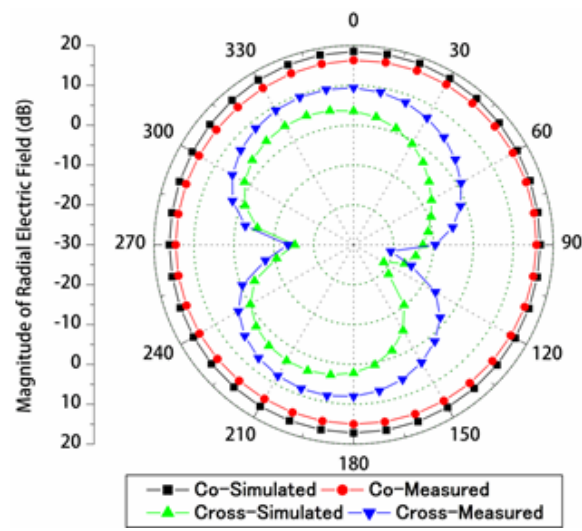

a)

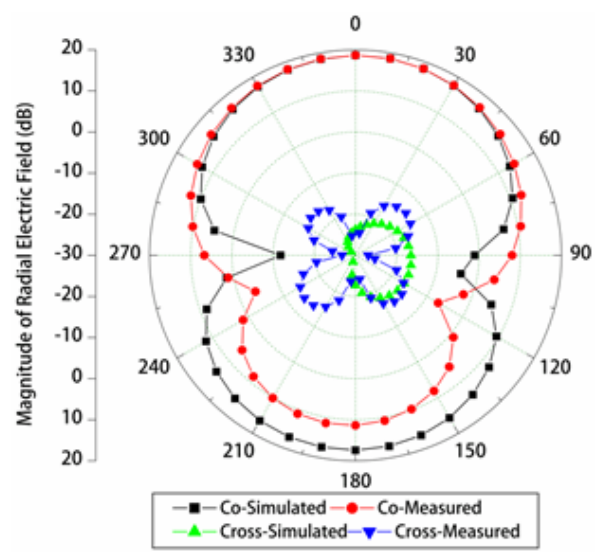

b) 


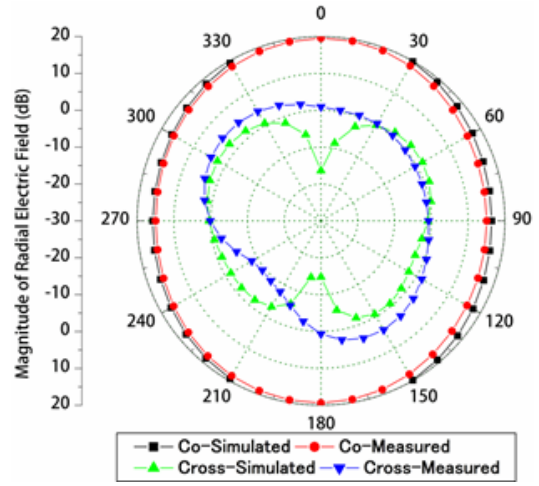

c)

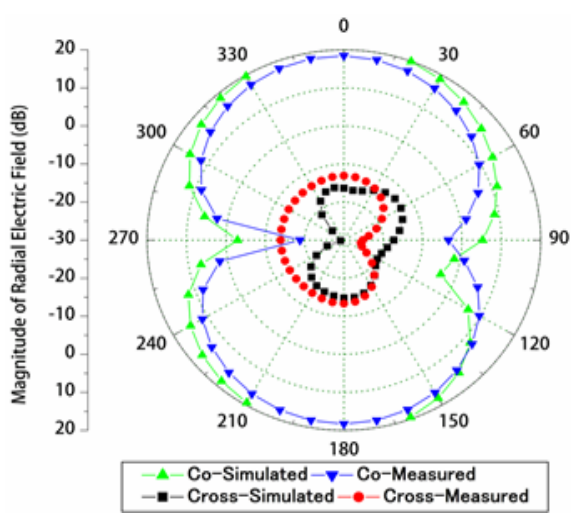

d)

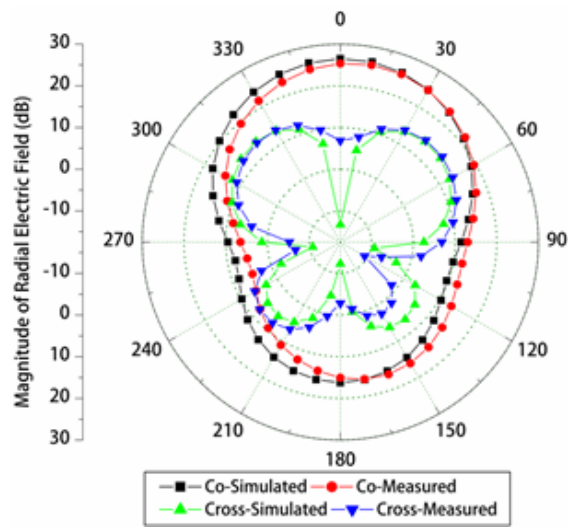

e)

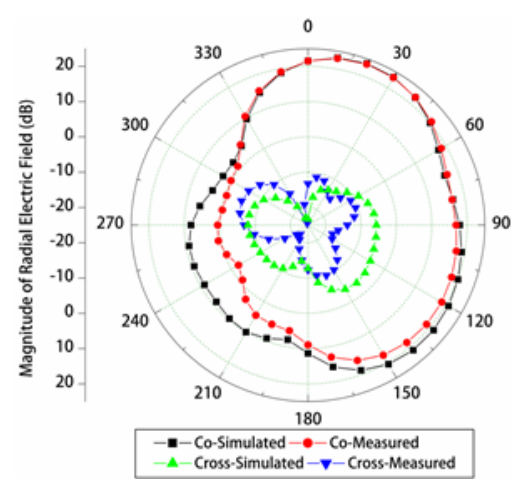

f)

Fig. 7. Simulated and measured E-plane and H-plane co \& cross-polarization level at a) $5.7 \mathrm{GHz}-\mathrm{E}-$ plane; b) $5.7 \mathrm{GHz}-\mathrm{H}-$ plane; c) $8.2 \mathrm{GHz}-\mathrm{E}-$ plane; d) 8.2 GHz-H-plane; e) $11.2 \mathrm{GHz}-\mathrm{E}-$ plane; f) $11.2 \mathrm{GHz}-\mathrm{H}$-plane.

\section{CONCLUSION}

The proposed antenna exhibits ultra-wideband behaviour between $4.86 \mathrm{GHz}$ and $13.60 \mathrm{GHz}$ frequency with the improved antenna performance. A comparative analysis is performed and shown in Table I for validation of the proposed antenna in modern applications for $\mathrm{C} / \mathrm{X} / \mathrm{Ku}$ band applications.

TABLE I

COMPARATIVE Study OF THE PROPOSED ANTENNA With RePORTED ANTENNAS FOR C/X/KU BAND APPLICATIONS

\begin{tabular}{|c|l|l|l|}
\hline Refs. & $\begin{array}{l}\text { Antenna size, } \mathbf{m m}^{2} \\
\text { (Substrate) }\end{array}$ & $\begin{array}{l}\text { Frequency range } \\
\text { /Bandwidth, } \\
\text { GHz }\end{array}$ & $\begin{array}{l}\text { Peak gain, } \\
\text { dBi }\end{array}$ \\
\hline$[16]$ & $\begin{array}{l}30 \times 28=840 \\
\left(\text { FR4 Epoxy, } \varepsilon_{\mathrm{r}}=4.6\right)\end{array}$ & $\begin{array}{l}(3-11) / 8 \\
(3.19-11.24) / 8.05\end{array}$ & 2.6 \\
\hline$[17]$ & $\begin{array}{l}24 \times 25=600 \\
\left(\text { FR4 Epoxy, } \varepsilon_{\mathrm{r}}=4.6\right)\end{array}$ & $(3.00-12.00) / 9$ & 5 \\
\hline$[18]$ & $\begin{array}{l}25 \times 25=625 \\
(\mathrm{RT} / \mathrm{Duroid} 5880, \\
\left.\varepsilon_{\mathrm{r}}=2.2\right)\end{array}$ & $\begin{array}{l}(1.55-8.55) / 7 \\
(8 \times 50=2400 \\
\left(\mathrm{Glass}, \mathrm{PTFE}, \varepsilon_{\mathrm{r}}=2.5\right)\end{array}$ & 4 \\
\hline$[19]$ & $\begin{array}{l}3.14 \times 20^{2}=1256.64 \\
\left(\mathrm{Glass}, \mathrm{PTFE}, \varepsilon_{\mathrm{r}}=2.4\right)\end{array}$ & $(4.34-12.75) / 8.41$ & 3.2 \\
\hline$[20]$ & $\begin{array}{l}22 \times 18=396 \\
\left(\mathrm{FR} 4 \text { Epoxy, } \varepsilon_{\mathrm{r}}=4.4\right)\end{array}$ & $(4.86-13.66) / 8.8$ & 4 \\
\hline Proposed & & & 4 \\
\hline
\end{tabular}

The comparative study is carried out in terms of the size of antenna structure, substrate material, impedance bandwidth and peak gain of the antenna. From perusal of Table I, it is observed that the patch area $\left(396 \mathrm{~mm}^{2}\right)$ of the proposed antenna is smaller than the antennas reported in [16]-[20] by a factor of $2.12,1.51,1.57,6.06$ and 3.17, respectively. Hence, the compact size antenna can easily be imbedded in small devices and MMICs for modern applications. However, the impedance bandwidth (4.86 to 13.66)/8.8 GHz of the proposed antenna is greater than the impedance bandwidth of the antennas reported in [16], [17], [19], [20] by $800 \mathrm{MHz}$, $750 \mathrm{MHz}, 1800 \mathrm{MHz}$ and $390 \mathrm{MHz}$, respectively, and lesser than that of the antenna reported in [18] by $200 \mathrm{MHz}$.

From the comparative overview of the peak gain (dBi) between the proposed antenna and reported antennas, it can be observed that peak gain of the proposed patch antenna is greater than that of antennas reported in [17], [20], equal to that of the antenna in [19] and marginally smaller than that of the antennas reported in [16], [18].

Comparative overview of the proposed design suggests that the proposed antenna is novel in terms of compactness $\left(396 \mathrm{~mm}^{2}\right)$, ultra-wide bandwidth capability $(8.8 \mathrm{GHz})$ and acceptable gain $(4 \mathrm{dBi})$ and it is a suitable candidate for $\mathrm{C} / \mathrm{X} / \mathrm{Ku}$ band applications.

In the present design, $75.25 \%$ of $\left(1600 \mathrm{~mm}^{2}\right)$ of $\mathrm{X} / \mathrm{Ku}$ band antenna [21], $71.7 \%$ of $\left(1400 \mathrm{~mm}^{2}\right)$ of $\mathrm{Ku} / \mathrm{K}$ and antenna [22], $90.1 \%$ of $\left(4000 \mathrm{~mm}^{2}\right)$ of $\mathrm{X}$ band antenna [23], $85.3 \%$ of $\left(2700 \mathrm{~mm}^{2}\right)$ of $\mathrm{X}$ band antenna [24], and $92.6 \%$ of $\left(5400 \mathrm{~mm}^{2}\right)$ of $\mathrm{C}$ band [25] reduction in antenna size are fairly achieved. The proposed antenna also has simple geometry to realise as compared to other designs at the operating bands $(\mathrm{C} / \mathrm{X} / \mathrm{Ku})$. 
The proposed antenna finds the application in UWB standards of Europe (6-8.5 GHz band with no restrictions by Electronic Communications Committee (ECC)), Japan (7.2510.25 GHz unlicensed band by the Ministry of Internal Affairs \& Communications (MICs)), Korea (7.2-10.2 GHz band with no restrictions by the Electronics and Telecommunications Research Institute (ETRI)) and Singapore (6-9 GHz band with no restrictions by the Infocomm Development Authority (IDA)) [7].

\section{REFERENCES}

[1] V. Arun and L. R. Karl Marx, "Micro-Controlled Tree Shaped Reconfigurable Patch Antenna With RF-Energy Harvesting," Wirel. Pers. Commun., Vol. 94, No. 4, pp. 2769-2781, Jun. 2017. https://doi.org/10.1007/s11277-017-3975-Z

[2] S. Selvan, M. Zaman, R. Gobbi, and H. Y. Wong, "Recent Advances in the Design and Development of Radio Frequency-Based Energy Harvester for Powering Wireless Sensors: A Review," J. Electromagn Waves Appl., Vol. 32, No. 16, pp. 2110-2134, Nov. 2018. https://doi.org/10.1080/09205071.2018.1497548

[3] M. T. Islam, M. Samsuzzaman, M. N. Rahman, and M. T. Islam, "A Compact Slotted Patch Antenna for Breast Tumor Detection," Microw. Opt. Technol. Lett., Vol. 60, No. 7, pp. 1600-1608, Jul. 2018. https://doi.org/10.1002/mop.31215

[4] B. Mishra, V. Singh, and R. Singh, "Gap Coupled Dual-Band Petal Shape Patch Antenna for Wlan / Wimax Applications," Adv. Electr. Electron. Eng., Vol. 16, No. 2, Jun. 2018. https://doi.org/10.15598/aeee.v16i2.2416

[5] J. Zaid, M. Farahani, and T. A. Denidni, "Magneto-Dielectric SubstrateBased Microstrip Antenna for RFID Applications," IET Microwaves, Antennas Propag., Vol. 11, No. 10, pp. 1389-1392, Aug. 2017. https://doi.org/10.1049/iet-map.2016.0931

[6] M. Tighezza, S. K. A. Rahim, and M. T. Islam, "Flexible Wideband Antenna For 5G Applications," Microw. Opt. Technol. Lett., Vol. 60, No. 1, pp. 38-44, Jan. 2018. https://doi.org/10.1002/mop.30906

[7] R. Cicchetti, E. Miozzi, and O. Testa, "Wideband and UWB Antennas for Wireless Applications: A Comprehensive Review," Int. J. Antennas Propag., Vol. 2017, pp. 1-45, 2017. https://doi.org/10.1155/2017/2390808

[8] B. Mishra, V. Singh, R. K. Singh, N. Singh, and R. Singh, "A Compact UWB Patch Antenna with Defected Ground for $\mathrm{Ku} / \mathrm{K}$ Band Applications," Microw. Opt. Technol. Lett., Vol. 60, No. 1, pp. 1-6, Jan. 2018. https://doi.org/10.1002/mop.30911

[9] J. Zhang and Z. Shen, "Dual-Band Shared-Aperture UHF/UWB RFID Reader Antenna of Circular Polarization," Ieee Trans. Antennas Propag., Vol. 66, No. 8, pp. 3886-3893, Aug. 2018. https://doi.org/10.1109/TAP.2018.2839883

[10] Federal Communications Commission Report, 2002. https://Transition.Fcc.Gov/Bureaus/Engineering_Technology/Orders/20 02/Fcc02048.Pdf

[11] T. K. Saha, T. N. Knaus, A. Khosla, and P. K. Sekhar, "A CPW-Fed Flexible UWB Antenna for IoT Applications," Microsyst. Technol., Dec. 2018. https://doi.org/10.1007/s00542-018-4260-0

[12] F. Mouhouche, A. Azrar, M. Dehmas, and K. Djafri, "Design A Compact Uwb Monopole Antenna with Triple Band-Notched Characteristics Using EBG Structures," Frequenz, Vol. 72, No. 11-12, pp. 479-487, Nov. 2018. https://doi.org/10.1515/freq-2018-0069

[13] N. M. Awad and M. K. Abdelazeez, "Multislot Microstrip Antenna for Ultra-Wide Band Applications," J. King Saud Univ. - Eng. Sci., Vol. 30, No. 1, pp. 38-45, Jan. 2018. https://doi.org/10.1016/j.jksues.2015.12.003

[14] S. Kundu and S. K. Jana, "A Compact Umbrella Shaped Uwb Antenna for Ground-Coupling GPR Applications," Microw. Opt. Technol. Lett., Vol. 60, No. 1, pp. 146-151, Jan. 2018. https://doi.org/10.1002/mop.30928

[15] M. K. Khandelwal, B. K. Kanaujia, and S. Kumar, "Defected Ground Structure: Fundamentals, Analysis, and Applications in Modern Wireless Trends," Int. J. Antennas Propag., Vol. 2017, pp. 1-22, 2017. https://doi.org/10.1155/2017/2018527
[16] N. A. Murugan, R. Balasubramanian, and H. R. Patnam, "Printed UltraWideband Monopole U-Slotted Antenna for Triple Band-Rejection," $J$. Electromagn. Waves Appl., Vol. 30, No. 12, pp. 1532-1544, Aug. 2016. https://doi.org/10.1080/09205071.2016.1202782

[17] G. Kumar, H. S. Mewara, and M. M. Sharma, "U-Shape Ground Defected Monopole Antenna for UWB Applications," In 2015 International Conference on Computational Intelligence and Communication Networks (Cicn), 2015, pp. 46-49. https://doi.org/10.1109/CICN.2015.18

[18] H. Li, L. Kang, D.-W. Mi, and Y.-Z. Yin, "Simple Dual Band-Notched UWB Antenna Loaded with Single U-Shaped Resonator," Microw. Opt. Technol. Lett., Vol. 57, No. 9, pp. 2129-2134, Sep. 2015. https://doi.org/10.1002/mop.29283

[19] K. Mondal and P. P. Sarkar, "U-Shape Broadband Monopole Antenna With Modified Ground Plane," Microw. Opt. Technol. Lett., Vol. 58, No. 11, pp. 2544-2547, Nov. 2016. https://doi.org/10.1002/mop.30093

[20] K. Mandal and P. P. Sarkar, "A Compact Low Profile Wideband UShape Antenna With Slotted Circular Ground Plane," AEU - Int. J. Electron. Commun., Vol. 70, No. 3, pp. 336-340, Mar. 2016. https://doi.org/10.1016/j.aeue.2015.12.011

[21] M. M. Islam, M. R. I. Faruque, W. Hueyshin, J. S. Mandeep, and T. Islam, "A Double Inverted F-Shape Patch Antenna for Dual-Band Operation," Int. J. Antennas Propag., Vol. 2014, pp. 1-8, 2014. https://doi.org/10.1155/2014/791521

[22] M. R. Ahsan, M. T. Islam, M. Habib Ullah, R. W. Aldhaheri, nd M. M. Sheikh, "A New Design Approach for Dual-Band Patch Antenna Serving Ku/K Band Satellite Communications," Int. J. Satell. Commun. Netw., Vol. 34, No. 6, pp. 759-769, Nov. 2016. https://doi.org/10.1002/sat.1130

[23] S. Jam and H. Malekpoor, "Analysis on Wideband Patch Arrays Using Unequal Arms With Equivalent Circuit Model in X-Band," IEEE Antennas Wirel. Propag. Lett., Vol. 15, pp. 1861-1864, 2016. https://doi.org/10.1109/LAWP.2016.2541179

[24] J. Kumar, B. Basu, F. A. Talukdar, and A. Nandi, "X-Band Antenna Printed on A Multilayered Substrate," IET Microwaves, Antennas Propag., Vol. 11, No. 11, pp. 1504-1509, Sep. 2017. https://doi.org/10.1049/iet-map.2017.0197

[25] S. Gotra, Z. Hashim, S. Pani, M. R. Tripathy, and A. Banwari, "C-Band Microstrip Patch Linear Array Antenna for Microwave Radio Relay," CSI Trans. ICT, Vol. 4, No. 2-4, pp. 151-155, Dec. 2016. https://doi.org/10.1007/s40012-016-0101-4

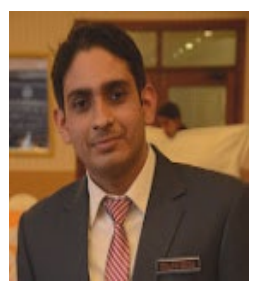

Ajay Kumar Dwivedi is a Research Scholar at the Electronics \& Communication Department of the Indian Institute of Information Technology Allahabad, India. He received his $\mathrm{M}$. Tech. in wireless communication engineering from Sam Higginbottom University of Agriculture, Technology and Sciences, Deemed University, Allahabad, India, in 2015 , B. Tech. in electronics \& communication engineering from the UPTU, Lucknow, India, in 2010. His research interests include RF \& microwave, wireless communication, antenna theory, dielectric resonator antenna, MIMO DRA.

E-mail: res2018505@iiita.ac.in

ORCID ID: https://orcid.org/0000-0003-1146-0902

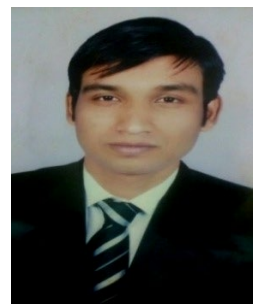

Brijesh Mishra was born in Azamgarh district of U.P. India in 1988. He received B. Tech. degree in electronics and communication engineering from Uttar Pradesh Technical University in 2010 and $\mathrm{M}$. Tech. degree in electronic engineering from the University of Allahabad in 2012. He obtained his D. Phil. degree from the University of Allahabad in 2018. Currently he is working as an Assistant Professor (NPIU-MHRD) at Madan Mohan Malaviya University of Technology, Gorakhpur (UP), India. His research interests include modelling, simulation and fabrication of RF devices and circuits and its applications. He has published many research articles in the field of microwave engineering and he is currently working on the two research projects funded by the World Bank.

E-mail: brijesh.mishra0933@gmail.com,bmec@mmmut.ac.in ORCID ID: https://orcid.org/0000-0002-2535-7159 


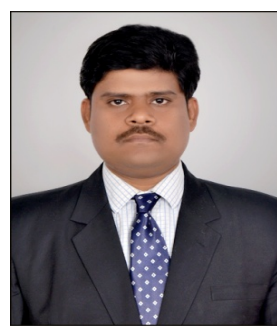

Vivek Singh was born in Allahabad district of U.P. in 1987. He obtained his B. Tech. degree in electronics and communication engineering from Uttar Pradesh Technical University in 2009 and

$\mathrm{M}$. Tech. degree in electronics engineering from the University of Allahabad in 2012. He obtained his D. Phil. degree in 2019 from the University of Allahabad. Currently he is working as an Assistant Professor at Shambhunath Institute of Engineering and Technology, Prayagraj, (UP), India. His of RF devices and circuits and its applications.

E-mail: vivek.10singh@gmail.com

ORCD ID: https://orcid.org/0000-0001-7569-0104

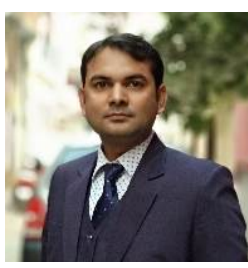

Pramod Narayan Tripathi received B. Tech. degree in electronics and communication engineering from Uttar Pradesh Technical University, India, in 2008 and M. Tech. degree in electronics and communication engineering, communication system engineering from SHUATS University, India, in 2012. He is currently a Doctoral student at Moscow Institute of Physics and Technology, State University, and microwave engineering. Moscow, Russia. His area of interest includes antenna

E-mail: pntripathi@phystech.edu ORCID ID: https://orcid.org/0000-0002-7303-5234

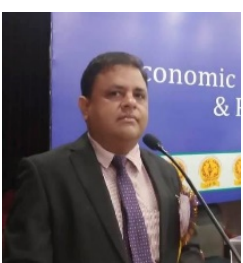

Dr. Ashutosh Kumar Singh received his M. Tech degree from MNNIT Allahabad and Doctoral degree from the Indian Institute of Information Technology, Allahabad, India. Currently, he is an Assistant Professor at the Electronics and Communication Engineering Department at the Indian Institute of Information Technology, Allahabad, India. His research interests include control systems, electronic circuits, networked control systems, and practical applications of control system theory, antenna theory.

E-mail: ashutosh_singh@iiita.ac.in

ORCID ID: https://orcid.org/0000-0001-6342-8918 